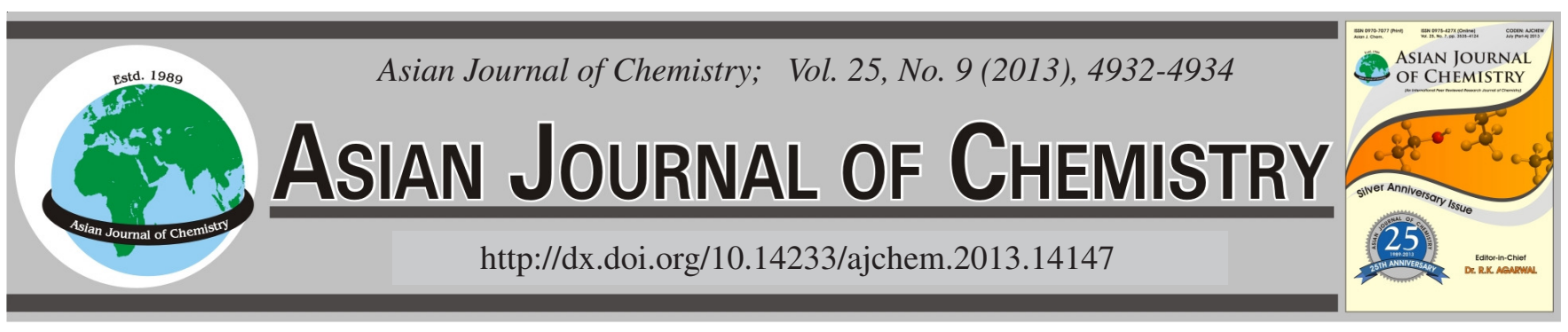

\title{
Sesquiterpene Glucosides from Nicotiana tabacum and Their Biological Activity
}

Guangyu-Yu Yang $^{1}$, Wei ZhaO ${ }^{1}$, Yong-Kuan Chen $^{1}$, Zhang-Yu Chen $^{1}$, Qiufen $\mathrm{Hu}^{2}$ and Ming-Ming MiaO ${ }^{1, *}$

${ }^{1}$ Key Laboratory of Tobacco Chemistry of Yunnan Province, Yunnan Academy of Tobacco Science, Kunming 650106, P.R. China ${ }^{2}$ Key Laboratory of Ethnic Medicine Resource Chemistry (Yunnan University of Nationalities), State Ethnic Affairs Commission \& Ministry of Education, Kunming 650031, P.R. China

*Corresponding author: E-mail: mmmiao@cyats.com; huqiufena@yahoo.com.cn

\begin{abstract}
A new sesquiterpene glucoside (1), together with two known sesquiterpene glucosides (2-3) were isolated from the leaves of Nicotiana tabacum. Their structures were elucidated by spectroscopic methods, including extensive ${ }^{1} \mathrm{D}$ and ${ }^{2} \mathrm{D}$ NMR techniques. Compounds $\mathbf{1 - 3}$ were tested for their anti HIV-1 activities and cytotoxicity. The results showed that compounds $\mathbf{1 - 3}$ have weak cytotoxic abilities and anti HIV-1 bioctivities, respectively.

Key Words: Nicotiana tabacum, Sesquiterpene glucosides, Anti HIV-1 activitiy, Cytotoxicity.
\end{abstract}

\section{INTRODUCTION}

Nicotiana tabacum L. belongs to Solanaceae family. It is one of the most commercially valued agricultural crops in the world $^{1,2}$. In addition to being used in cigarette industry, $N$. tabacum is also used as insecticide, anesthetic, diaphoretic, sedative and emetic agents in Chinese folklore medicine because of containing many useful chemical compounds ${ }^{1,3-5}$.

In previous work, a number of bioactive compounds, such as sesquiterpenes ${ }^{6,7}$, diterpenoids ${ }^{8-10}$, alkaloids ${ }^{11,12}$, phenols ${ }^{13}$ and their homologous, were isolated from this plant. Motivated by search for bioactive metabolites from this plant, the investigation on the chemical constituents of the leaves of $N$. tabacum was carried out. As a result, a new sesquiterpene glucoside (1), together with two known sesquiterpene glucosides (2-3), were isolated from this plant. In addition, the anti HIV-1 activities and cytotoxicities of compounds 1-3 were evaluated, respectively. This work deals with the isolation, structural elucidation and biological activities of the compounds.

\section{EXPERIMENTAL}

General experimental procedures: Optical rotation was measured in Horiba SEPA-300 High Sensitive Polarimeter. IR spectra were obtained in $\mathrm{KBr}$ disc on a Bio-Rad Wininfmred spectrophotometer. ESI-MS were measured on a VG Auto Spec-3000 MS spectrometer. ${ }^{1} \mathrm{H},{ }^{13} \mathrm{C}$ and ${ }^{2} \mathrm{D}$ NMR spectra were recorded on Bruker DRX-500 instrument with TMS as internal standard. Column chromatography was performed on silica gel (200-300 mesh), or on silica gel H (10-40 mm, Qingdao
Marine Chemical Inc., China). Second separate was used an Agilent 1100 HPLC equipped with ZORBAX-C ${ }_{18}(21.2 \mathrm{~nm} \times$ $250 \mathrm{~nm}, 7.0 \mu \mathrm{m}$ ) column and DAD detector.

Plant material: The leaves of nicotiana tabacum L (tobacco leaves) was collected from Yuxi County, Yunnan Province, P.R. China, in September 2009.

Extraction and isolation: The air-dried and powdered leaves of nicotiana tabacum $(2.5 \mathrm{~kg})$ were extracted with $70 \%$ aqueous ethanol $(3.0 \mathrm{~L} \times 3 \mathrm{~L}, 24 \mathrm{~h}$ each) at room temperature and the extract was concentrated under vacuum condition. The dried extract (68.5 g) was applied to Si gel (200-300 mesh) column chromatography eluting with a $\mathrm{CHCl}_{3}-\mathrm{Me}_{2} \mathrm{CO}$ gradient system $(9: 1,8: 2,7: 3,6: 4,5: 5,2: 1)$ to give six fractions A-F. Fraction A3 (7:3, 7.21 g) was subjected to silica gel column chromatography using $\mathrm{CHCl}_{3}-\mathrm{MeOH}$ and preparative HPLC (30\% MeOH- $\mathrm{H}_{2} \mathrm{O}$, flow rate $12 \mathrm{~mL} / \mathrm{min}$ ) to give $\mathbf{1}$ (22.6 mg), 2 (39.8 mg) and 3 (33.5 mg).

Anti HIV-1 assay: The cytotoxicity assay against C8166 cells (CC50) was assessed using the MTT method and anti HIV-1 activity was evaluated by the inhibition assay for the cytopathic effects of HIV-1 $\left(\mathrm{EC}_{50}\right)^{14}$. Compound $\mathbf{1}$ shows anti HIV-1 activity with $\mathrm{EC}_{50}$ of $5.22 \mu \mathrm{g} / \mathrm{mL}, \mathrm{CC} 50$ of above 200 $\mu \mathrm{g} / \mathrm{mL}$ and TI (therapeutic index) valve of above 38.3. Compound 2 shows anti HIV-1 activity with $\mathrm{EC}_{50}$ of $4.73 \mu \mathrm{g}$ / $\mathrm{mL}, \mathrm{CC} 50$ of $105.6 \mu \mathrm{g} / \mathrm{mL}$ and TI of 20.58. Compound $\mathbf{3}$ shows anti HIV-1 activity with $\mathrm{EC}_{50}$ of $6.15 \mu \mathrm{g} / \mathrm{mL}, \mathrm{CC} 50$ of 88.5 $\mu \mathrm{g} / \mathrm{mL}$ and TI valve of 14.4 .

Cytotoxicity assays: The cytotoxicity tests for the isolates were performed using a previously reported procedure ${ }^{15}$. All 
treatments were performed in triplicate. In the MTT assay, the $\mathrm{IC}_{50}$ was defined as the concentration of the test compound resulting in a $50 \%$ reduction of absorbance compared with untreated cells. The cytotoxic abilities against HL-60, HepG2, KB and MDA-MB-231 tumor cell lines by MTT-assay (with camptothecin as the positive control) were shown in Table-1.

\begin{tabular}{ccccc}
\multicolumn{5}{c}{ TABLE-1 } \\
CYTOTOXICITIES OF COMPOUNDS 1-3 \\
\hline \multirow{2}{*}{ Compounds } & \multicolumn{4}{c}{ Cell lines } \\
\cline { 2 - 5 } & HL-60 & HepG2 & KB & MDA-MB-231 \\
\hline $\mathbf{1}$ & 4.42 & 6.05 & 2.22 & 15.50 \\
$\mathbf{2}$ & 5.90 & 13.83 & 5.96 & 4.21 \\
$\mathbf{3}$ & 5.50 & 7.68 & 5.41 & 11.29 \\
Camptothecin & 1.78 & 1.01 & 1.68 & 2.26 \\
\hline
\end{tabular}

Data are $\mathrm{IC}_{50}$ values in $\mu \mathrm{mol} / \mathrm{L}$. For a compound to be deemed effective, an $\mathrm{IC}_{50}$ value $<100 \mu \mathrm{mol} / \mathrm{L}$ is required. Camptothecin was used as a positive control. HL-60, human acute promyelocytic leukemia; Hep-G2, human hepatocellular carcinoma; KB, human oropharyngeal epidermoid carcinoma; MDA-MB-231, human breast cancer cells.

Nicotterpene A: Obtained as a viscous oil; $[\alpha]_{24.5}^{\mathrm{D}}-15.8$ (c 0.22, MeOH); UV (MeOH), $\lambda_{\max }(\log \varepsilon) 248$ (3.86), 210 (4.38) nm; IR (KBr, $\left.v_{\max }, \mathrm{cm}^{-1}\right): 3418,2968,2870,1682,1634$, 1550, 1462, 1435, 972,875; ${ }^{1} \mathrm{H}$ and ${ }^{13} \mathrm{C}$ NMR data $\left(\mathrm{C}_{5} \mathrm{D}_{5} \mathrm{~N}\right.$, 500 and $125 \mathrm{MHz}$ ), Table-2; ESIMS (positive ion mode) $\mathrm{m} / \mathrm{z}$ 435; HRESIMS (positive ion mode) $\mathrm{m} / \mathrm{z} 435.1900[\mathrm{M}+\mathrm{Na}]^{+}$ (calcd. (\%) 435.1995 for $\mathrm{C}_{20} \mathrm{H}_{24} \mathrm{O}_{8} \mathrm{Na}$ ).

\begin{tabular}{ccc}
\multicolumn{3}{c}{ TABLE-2 } \\
${ }^{1} \mathrm{H}$ AND ${ }^{13} \mathrm{CNMR}^{\mathrm{N}}$ DATA OF COMPOUNDS $\mathbf{1} \mathrm{IN} \mathrm{C}_{5} \mathrm{D}_{5} \mathrm{~N}$ \\
\hline No. & $\delta_{\mathrm{C}}(\mathrm{mult})$. & $\delta_{\mathrm{H}}(\mathrm{mult}, J, \mathrm{~Hz})$ \\
\hline 1 & $50.2 \mathrm{~s}$ & - \\
2 & $46.3 \mathrm{~d}$ & $2.58, \mathrm{~m}$ \\
3 & $81.2 \mathrm{~d}$ & $4.47, \mathrm{~d}, J=8.1$ \\
4 & $198.3 \mathrm{~s}$ & - \\
5 & $124.2 \mathrm{~d}$ & $5.93 \mathrm{~s}$ \\
6 & $168.5 \mathrm{~s}$ & - \\
7 & $41.8 \mathrm{t}$ & $1.72, \mathrm{~m}, 2.43, \mathrm{~m}$ \\
8 & $38.9 \mathrm{~d}$ & $2.36 \mathrm{~m}$ \\
9 & $31.6 \mathrm{t}$ & $1.90 \mathrm{~m}, 1.48 \mathrm{~m}$ \\
10 & $32.7 \mathrm{t}$ & $1.26 \mathrm{~m}, 1.69 \mathrm{~m}$ \\
11 & $152.3 \mathrm{~s}$ & - \\
12 & $106.5 \mathrm{t}$ & $5.06 \mathrm{brs}, 4.98 \mathrm{brs}$ \\
13 & $62.4 \mathrm{t}$ & $4.35 \mathrm{~s}$ \\
14 & $21.4 \mathrm{q}$ & $1.72 \mathrm{~s}$ \\
15 & $13.2 \mathrm{q}$ & $1.08, \mathrm{~d}, J=7.0$ \\
$1^{\prime}$ & $104.2 \mathrm{~d}$ & $5.22, \mathrm{~d}, J=8.1$ \\
$2^{\prime}$ & $74.2 \mathrm{~d}$ & $4.15, \mathrm{~m}$ \\
$3^{\prime}$ & $78.5 \mathrm{~d}$ & $3.92, \mathrm{~m}$ \\
$4^{\prime}$ & $71.6 \mathrm{~d}$ & $4.34, \mathrm{~m}$ \\
$5^{\prime}$ & $78.8 \mathrm{~d}$ & $4.22, \mathrm{~m}$ \\
$6^{\prime}$ & $63.5 \mathrm{t}$ & $4.30, \mathrm{~m}, 4.56, \mathrm{~m}$ \\
\hline
\end{tabular}

\section{RESULTS AND DISCUSSION}

A $70 \%$ aq. methanol extract prepared from the leaves of $N$. tabacum was subjected repeatedly to column chromatography on silica gel, sephadex LH-20, RP-18 and preparative HPLC to afford compounds $\mathbf{1 - 3}$ (Fig. 1), including a new sesquiterpene, nicotterpene A (1), together with two known

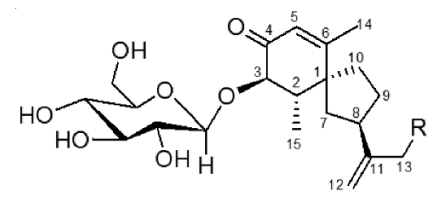

(1) $\mathrm{R}=\mathrm{OH},(2) \mathrm{R}=\mathrm{H}$

Fig. 1. Structure of compounds $\mathbf{1 - 3}$

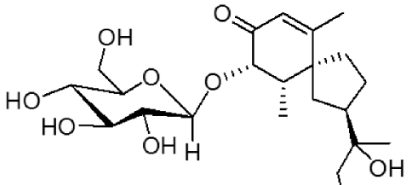

(3)

$\mathrm{OH}$ sesquiterpenes, 3-hydroxysolavetivone- $\beta$-D-glucoside A (2) ${ }^{6}$, $11 \mathrm{R}, 12$-dihydroxy-6(7)-spirovetiven-8-one-9-O- $\beta$-Dglucopyranoside $(\mathbf{3})^{7}$.

Compound 1 was obtained as a viscous oil and gave a quasi-molecular ion $[\mathrm{M}+\mathrm{Na}]^{+}$at $\mathrm{m} / \mathrm{z} 435.1990$ (calcd. (\%) 435.1995) in the HRESI-MS, consistent with the elemental composition $\mathrm{C}_{21} \mathrm{H}_{32} \mathrm{O}_{8} \mathrm{Na}$. The ${ }^{1} \mathrm{H}$ NMR spectrum of $\mathbf{1}$ revealed the presence of one doublet methyl group at $\delta_{\mathrm{H}} 1.08(\mathrm{~d}, J=$ $7.0 \mathrm{~Hz}$ ), one singlet methyl group at $\delta_{\mathrm{H}} 1.72(\mathrm{~s})$, one olefinic proton at $\delta_{\mathrm{H}} 5.93(\mathrm{~s})$ and two exo-olefinic protons at $\delta_{\mathrm{H}} 4.98$ (brs) and 5.06 (brs). Analysis of the ${ }^{13} \mathrm{C}$ NMR spectrum, which has 21 signals, allowed the identification of one a,b-unsaturated carbonyl group at $\delta_{\mathrm{C}} 198.3,168.5,124.2$, one terminal double bond at $\delta_{\mathrm{C}} 147.8,109.1$, one quaternary carbon at $\delta_{\mathrm{C}} 50.2$, two methyl carbons at $\delta_{\mathrm{C}} 13.2,21.4$ and an oxidated methylene carbon at $\delta_{\mathrm{C}} 63.5$. The presence of one sugar was confirmed from one anomeric proton at $\delta_{\mathrm{H}} 5.22(\mathrm{~d}, J=8.1 \mathrm{~Hz})$, one anomeric carbon at $\delta_{\mathrm{C}} 104.2$ and five oxygenated carbons at $\delta_{\mathrm{C}} 74.2,78.5,71.6,78.8,63.5$. All the spectral data suggested that 1 was a spirovetiven-type sesquiterpene glycoside 6 . The location of the sugar moiety at $\mathrm{C}-3$ was established according to the correlation observed between $\mathrm{H}-1$ ' (at $\delta_{\mathrm{H}} 5.22$ ) and $\mathrm{C}-3$ (at $\delta_{\mathrm{C}} 80.4$ ) in the HMBC experiment of $\mathbf{1}$ (Fig. 2). On acid hydrolysis, 1 afforded glucose, which was identified by coTLC with standard monosaccharide. The $\beta$-configuration for the glucose was determined from a large coupling constant value $(J=8.1 \mathrm{~Hz})$ of the anomeric proton at $\delta_{\mathrm{H}} 5.17$. The NMR spectral data of $\mathbf{1}$ were similar to those of the previously reported 3-hydroxysolavetivone- $\beta$-D-glucoside A (1), a sesquiterpene glucoside isolated from $N$. tabacum $^{6}$. The main differences between the two compounds were that a signal of the methyl carbon in $\mathbf{2}$ was changed to an oxidated methylene carbon in 1. This variation resulted from a methyl group (C13) was oxidated to a methylene group and this was supported by the HMBC correlations of $\mathrm{H}-13\left(\delta_{\mathrm{H}} 4.35 \mathrm{~s}\right)$ with $\mathrm{C}-8\left(\delta_{\mathrm{C}}\right.$ $38.9), \mathrm{C}-11\left(\delta_{\mathrm{C}} 152.3\right), \mathrm{C}-12\left(\delta_{\mathrm{C}} 106.5\right)$.

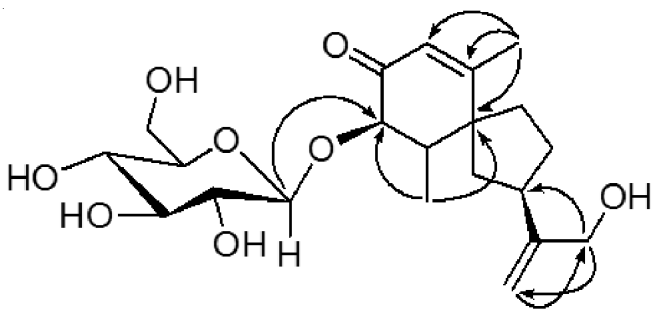

Fig. 2. Key HMBC ( $\mathrm{H} \curvearrowright \mathrm{C})$ correlations of $\mathbf{1}$

In compound 1, the NOESY cross peak from H-3 to Me15 suggested that $\mathrm{H}-3$ and Me- 15 are on the same side and the coupling constant $(J=8.1 \mathrm{~Hz})$ between $\mathrm{H}-2$ and $\mathrm{H}-3$ showed that the cyclohexenone of $\mathbf{1}$ adopted a half-chair conformation 
with $\mathrm{H}-2$ and $\mathrm{H}-3$ in a pseudoaxial position, since the bulky groups of glucose and methyl preferred an equatorial position. Consequently, the structure of $\mathbf{1}$ was determined and named nicotterpene A.

\section{ACKNOWLEDGEMENTS}

This project was supported financially by the Basic Research Foundation of Yunnan Tobacco Industry Co. Ltd. (2012JC01), and the Excelleng Scientific and Technological Team of Yunnan High School (2010CI08).

\section{REFERENCES}

1. The Editorial Committee of the Administration Bureau of Flora of China, Flora of China, Beijing Science and Technology Press, Beijing, Vol. 67 (2005).

2. T.W. Hu and Z. Mao, Tob. Control, 15, i37 (2006).

3. A. Rodgman and T.A. Perfetti, The Chemical Components of Tobacco and Tobacco Smoke, CRC Press, Taylor and Francis Group, Boca Raton, Florida (2008)
4. A.P. Cavender and M. Alban, J. Ethnobiol. Ethnomed., 5, 3 (2009).

5. I. Angkhana, S.J. Pei, B. Henrik and T. Chusie, J. Ethnopharm., 116, 134 (2008).

6. X. Feng, J.S. Wang, J. Luo and L.Y. Kong, J. Asian Nat. Prod. Res., 12, 252 (2010).

7. X. Feng, J.S. Wang, J. Luo and L.Y. Kong, J. Asian Nat. Prod. Res., 11, 675 (2009).

8. W. Inger, W. Ingrid, N. Kerstin, N. Toshiaki, R.E. Curt, W.R. William, Y. Noboru and Y. Chizuko, Acta Chem. Scand., 33b, 541 (1979).

9. Y. Shinozaki, T. Tobita, M. Mizutani and T. Matsuzaki, Biosci. Biotechnol. Biochem., 60, 903 (1996).

10. T. Petterson, A.M. Eklund and I. Wahlberg, J. Agric. Food Chem., 41, 2097 (1993).

11. X.C. Wei, S.C. Sumithran, A.G. Deaciuc, H.R. Burton, L.P. Bush, L.P. Dwoskin and P.A. Crooks, Life. Sci., 78, 495 (2005).

12. T. Braumann, G. Nicolaus, W. Hahn and H. Elmenhorst, Phytochemistry, 29, 3693 (1990).

13. D. Vereecke, E. Messens, K. Klarskov, A. Bruyn, M. Montagu and K. Goethals, Planta, 201, 342 (1997).

14. J.H. Wang, S.C. Tam, H. Huang, D.Y. Yang, Y.Y. Wang and Y.T. Zheng, Biochem. Biophys. Res. Commun., 317, 965 (2004).

15. T. Mosmann, J. Immunol. Methods, 65, 55 (1983). 